\title{
BMJ
}

\section{Hysterectomy, endometrial ablation, and levonorgestrel releasing intrauterine system (Mirena) for treatment of heavy menstrual bleeding: cost effectiveness analysis}

\author{
T E Roberts, professor of health economics, ${ }^{1}$ A Tsourapas, research fellow, ${ }^{1} \mathrm{~L}$ J Middleton, statistician, ${ }^{2} \mathrm{R}$ \\ Champaneria, research associate, ${ }^{2} \mathrm{JP}$ Daniels, senior research fellow, ${ }^{2} \mathrm{~K}$ G Cooper, consultant gynaecologist, ${ }^{3}$ \\ S Bhattacharya, professor of obstetrics and gynaecology, ${ }^{4} \mathrm{P}$ M Barton, senior lecturer in mathematical \\ modelling ${ }^{1}$
}

${ }^{1}$ Health Economics Unit, School of Health and Population Sciences,

Public Health Building, University of Birmingham, Birmingham B15 2TT, UK

${ }^{2}$ Birmingham Clinical Trials Unit, University of Birmingham, Birmingham

${ }^{3}$ Department of Obstetrics and Gynaecology, Aberdeen Royal

Infirmary, Foresterhill, Aberdeen AB25 2ZN

${ }^{4}$ Section of Applied Clinical Sciences, Division of Applied Health Sciences, School of

Medicine and Dentistry, University of Aberdeen, Aberdeen Maternity Hospital, Foresterhill, Aberdeen

Correspondence to: T E Roberts

T.E.Roberts@bham.ac.uk

Cite this as: BMJ 2011;342:d2202 doi:10.1136/bmj.d2202 levonorgestrel releasing intrauterine system (Mirena) for

\section{ABSTRACT}

Objective To undertake a cost effectiveness analysis comparing first and second generation endometrial ablative techniques, hysterectomy, and the treating heavy menstrual bleeding.

Design Model based economic evaluation with data from an individual patient data meta-analysis supplemented with cost and outcome data from published sources taking an NHS (National Health Service) perspective. A state transition (Markov) model was developed, the structure being informed by the reviews of the trials and clinical input. A subgroup analysis, one way sensitivity analysis, and probabilistic sensitivity analysis were also carried out.

Population Four hypothetical cohorts of women with heavy menstrual bleeding.

Interventions One of four alternative strategies: Mirena, first or second generation endometrial ablation techniques, or hysterectomy.

Main outcome measures Cost effectiveness based on incremental cost per quality adjusted life year (QALY). Results Hysterectomy is the preferred strategy for the first intervention for heavy menstrual bleeding. Although hysterectomy is more expensive, it produces more QALYs relative to other remaining strategies and is likely to be considered cost effective. The incremental cost effectiveness ratio for hysterectomy compared with Mirena is $£ 1440$ ( $€ 1633, \$ 2350)$ per additional QALY. The incremental cost effectiveness ratio for hysterectomy compared with second generation ablation is $£ 970$ per additional QALY.

Conclusion In light of the acceptable thresholds used by the National Institute for Health and Clinical Excellence, hysterectomy would be considered the preferred strategy for the treatment of heavy menstrual bleeding. The results concur with those of other studies but are highly sensitive to utility values used in the analysis.

\section{INTRODUCTION}

Heavy menstrual bleeding is a common problem ${ }^{1}$ that affects about 1.5 million women in England and
Wales. ${ }^{2}$ The condition prompts one in 20 women of reproductive age to consult her general practitioner and accounts for $20 \%$ of all referrals to gynaecology outpatients. ${ }^{2}$ Heavy menstrual bleeding can cause considerable distress to women by affecting their performance at work as well as social activities and leads to a measurable reduction in quality of life. ${ }^{3}$ Traditionally, the definitive treatment was surgery: in the past, by the age of 55 one in five women in the United Kingdom had had a hysterectomy, ${ }^{4}$ over half of which were for heavy menstrual bleeding. ${ }^{5}$

First line treatments for heavy menstrual bleeding include oral drug regimens such as tranexamic acid, mefenamic acid, and the combined contraceptive pill. More recently an alternative medical option is available in the levonorgestrel intrauterine system (Mirena). This intrauterine contraceptive device works to reduce menstrual loss by local release of progestogen and can be fitted in primary or secondary care. ${ }^{6}$ Surgical treatments include first and second generation endometrial ablation, which destroys the lining of the cavity of the uterus (endometrium). ${ }^{6}$ First generation techniques typically required direct hysteroscopic vision and include endometrial laser ablation, transcervical resection of the endometrium, and rollerball ablation. Second generation techniques are typically nonhysteroscopic, vision control is not required, and they tend to be easier to perform. These latter techniques include fluid filled thermal balloon endometrial ablation, radiofrequency (thermoregulated) balloon endometrial ablation, and microwave endometrial ablation (MEA). Hysterectomy, surgical removal of the uterus, was the only surgical solution until the advent of ablation techniques and is still used when other treatments fail. ${ }^{6}$

Between 2000 and 2005 the number of hysterectomies performed for heavy menstrual bleeding fell from over 20000 to just over 7000. Instead, 9701 women underwent endometrial ablation; over half of these (5457) were performed by means of second generation (non-hysteroscopic) techniques. ${ }^{67}$ The use of Mirena has increased concurrently, though its 


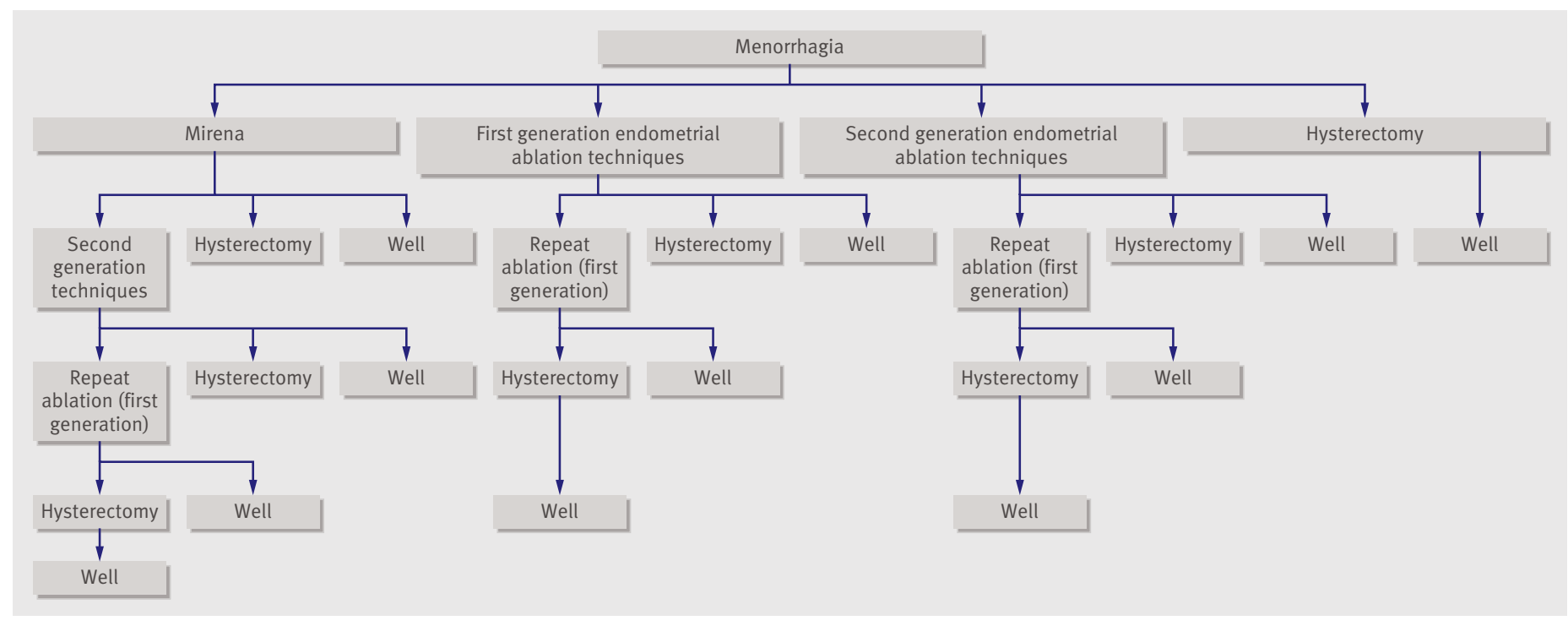

Fig 1 | Clinical pathways within model for determination of cost effectiveness of different treatments for heavy menstrual bleeding. Names of strategies denote first intervention undertaken

widespread use for contraception across many clinical settings in primary and secondary care means that it is difficult to gather accurate data on numbers prescribed for heavy menstrual bleeding. Though some follow-up studies have concentrated on short and medium term outcomes after hysterectomy and endometrial ablation, there have been few long term controlled comparisons of hysterectomy with ablation techniques in women with heavy menstrual bleeding. ${ }^{7}$

As part of a wider NIHR Health Technology Assessment project tasked to assess the existing evidence on effectiveness through a meta-analysis of non-oral treatments for heavy menstrual bleeding using data on individual patients, ${ }^{6}$ we carried out an economic evaluation to determine the relative cost effectiveness of the four alternative non-oral interventions - hysterectomy, first and second generation endometrial ablation, and Mirena-for the treatment of heavy menstrual bleeding. Although it is a non-surgical intervention, we included Mirena in the analysis for comparison primarily because it is the intervention that the National Institute for Health and Clinical (NICE) favours for this condition. ${ }^{8}$

\section{METHODS}

We have already published a systematic review and individual patient data meta-analysis of available evidence. ${ }^{7}$ Briefly, we used individual patient data as far as possible, supplemented with the trial data as necessary. Individual patient data on 2814 women were available from 17 of the 30 randomised controlled trials identified ( 14 trials ( 2448 women) for first versus second generation endometrial ablation; seven trials (1127 women) for hysterectomy versus first generation endometrial ablation; five trials (304 women) for second generation endometrial ablation versus Mirena; three trials (190 women) for first generation endometrial ablation versus Mirena; one trial
(236 women) for hysterectomy versus Mirena). Direct and indirect comparisons were made when appropriate to assess the effect of interventions on the primary outcome measure of patient's dissatisfaction.

Given the reliance on secondary data and the nature of available data, the model based economic evaluation takes the form of a cost utility analysis and was carried out from a UK National Health Service (NHS) perspective in a secondary care setting.

\section{Cost effectiveness model}

The model was developed through consultation within the research team, drawing on the requisite clinical and modelling expertise. We developed a new state transition (Markov) model in Microsoft Excel, using as a starting point an existing model developed by Garside et al. ${ }^{9}$ In running the model we compared the progress of a hypothetical cohort of women with heavy menstrual bleeding when they are treated by four alternative interventions: Mirena, first generation endometrial ablation techniques, second generation endometrial ablation techniques, and hysterectomy. We compared the four alternative interventions in four alternative treatment strategies. The pathway of the strategy is defined by the intervention that is tried first. For example, the second generation endometrial ablation strategy is so called because that is the intervention first in the pathway; if it works for any particular woman, her treatment will stop there. However, the pathways are constructed to follow logical clinical evidence based progression. Each progression in the pathway reflects the next likely option, assuming that the patient returns seeking further treatment because she is dissatisfied with the outcome from the previous treatment. So, for instance, the strategy referred to as second generation ablation might also include a repeat ablation and even a hysterectomy later in the strategy. We include a strategy to represent first generation 


\begin{tabular}{|c|c|c|c|}
\hline & Endometrial ablation & Hysterectomy & Mirena \\
\hline Menorrhagia & \multicolumn{3}{|c|}{ All women in cohort have preoperative heavy menstrual bleeding } \\
\hline Hysterectomy & $\begin{array}{l}\text { If women have symptoms after first ablation, they } \\
\text { might choose to have hysterectomy. Hysterectomy } \\
\text { is also an option after failed repeat endometrial } \\
\text { ablation. This operation occurs } 6 \text { months after } \\
\text { decision. These women then follow the pathway } \\
\text { outlined in hysterectomy diagram (fig 3) }\end{array}$ & All women undergo hysterectomy & - \\
\hline $\begin{array}{l}\text { Endometrial } \\
\text { ablation } \\
\text { techniques }\end{array}$ & $\begin{array}{l}\text { Women undergo endometrial ablation by first or } \\
\text { second generation techniques }\end{array}$ & - & - \\
\hline $\begin{array}{l}\text { Complica- } \\
\text { tions }\end{array}$ & $\begin{array}{l}\text { After endometrial ablation, some women will } \\
\text { experience severe postoperative complications. } \\
\text { Perioperative complications are included in } \\
\text { endometrial ablation state }\end{array}$ & $\begin{array}{l}\text { After hysterectomy, some women will } \\
\text { experience severe postoperative } \\
\text { complications. Effects of these might } \\
\text { last for } 1 \text { month. Operative } \\
\text { complications are included in } \\
\text { hysterectomy state }\end{array}$ & - \\
\hline Well & $\begin{array}{l}\text { After endometrial ablation, complications, or } \\
\text { treatment failure, women are satisfied with } \\
\text { treatment }\end{array}$ & $\begin{array}{l}\text { After convalescence women are } \\
\text { satisfied with treatment }\end{array}$ & $\begin{array}{l}\text { After Mirena, women are satisfied with } \\
\text { treatment }\end{array}$ \\
\hline Mirena & - & - & All women have Mirena inserted \\
\hline Symptomatic & $\begin{array}{l}\text { After endometrial ablation, complications, or being } \\
\text { well, heavy menstrual bleeding might recur } \\
\text { (treatment failure) at any time. Women might be re- } \\
\text { treated (repeat ablation), become well, or have } \\
\text { hysterectomy after initial or repeat ablation }\end{array}$ & - & $\begin{array}{l}\text { After Mirena or being well, heavy } \\
\text { menstrual bleeding can recur (treatment } \\
\text { failure) at any time }\end{array}$ \\
\hline $\begin{array}{l}\text { Convales- } \\
\text { cence }\end{array}$ & - & $\begin{array}{l}\text { After hysterectomy both with and } \\
\text { without complications, period of } \\
\text { convalescence is experienced. This can } \\
\text { last up to } 3 \text { months }\end{array}$ & - \\
\hline Repeat & $\begin{array}{l}\text { Repeat ablation (rollerball)_if heavy menstrual } \\
\text { bleeding recurs postoperatively, women might } \\
\text { choose to have second endometrial ablation, } \\
\text { which occurs } 6 \text { months after initial ablation. Only } \\
\text { one repeat endometrial ablation is permitted and it } \\
\text { is always first generation technique (rollerball) }\end{array}$ & - & $\begin{array}{l}\text { Women can be re-treated, have second } \\
\text { generation endometrial ablation, or } \\
\text { remain symptomatic }\end{array}$ \\
\hline Death & $\begin{array}{l}\text { Death from natural causes is possible. For hysterec } \\
\text { might also die as direct result of surgical procedure }\end{array}$ & tomy and endometrial ablation, women & - \\
\hline
\end{tabular}

endometrial ablation and a separate strategy to represent second generation endometrial ablation. Although first generation ablation might sound like an approach that has been superseded by second generation ablative techniques, outcomes from first generation techniques are still acceptable, and the technique is sometimes considered more versatile than some second generation approaches. For example, they are used if visualising the cavity at time of treatment is deemed important. Furthermore, first generation ablative techniques must be the technique of choice when repeat treatments are required, whether or not the preceding treatment was first or second generation ablation. Neither of the ablative techniques preserves fertility. The only intervention that preserves fertility is Mirena. The hysterectomy strategy is offered to a woman for whom the only acceptable outcome is amenorrhoea. In the hysterectomy strategy, all other steps are bypassed and hysterectomy is the only intervention.

Figure 1 shows the clinical pathways on which the model is based. Health states are shown in boxes, and arrows show the transitions that can occur. The health states and pathways are the same for both types of endometrial ablation techniques. Table 1 presents a summary of the health states for each pathway.

In this model, the hypothetical cohort of patients moves between discrete health states to replicate the natural course of the condition, with each state having associated costs and quality of life. In such a model, transition probabilities, costs, and quality of life differ according to the use of the alternative techniques used to treat the clinical problem. The difference in outcome and costs between cohorts yields estimates of cost effectiveness.

We compared a cohort of 10000 eligible women for each strategy. The starting age of women in the model is 42 , as this is the mean age of women in all the ablation randomised controlled trials, and the period covered is a total of 10 years. ${ }^{6710} \mathrm{We}$ assume that all women will become menopausal at the age of 52, the average age of menopause in the UK. We considered these assumptions to reflect the evidence in the literature. ${ }^{6}$ These are also the assumptions used by earlier authors. ${ }^{8}$ Each model cycle lasts one month, representing the typical menstrual cycle. The death rate from causes other than procedures for heavy menstrual bleeding was based on values for women in the government actuary's 
Table 2 | Data used in model to determine cost effectiveness of different treatments for heavy menstrual bleeding

\begin{tabular}{lc} 
Background mortality rate (from life tables) & $\begin{array}{c}\text { Value and } \\
\text { source }\end{array}$ \\
\hline Proportion of women with symptoms (after initial ablation) who have repeat ablation* & 0.00015 \\
\hline Proportion of women with symptoms (after initial ablation) who have hysterectomy* & $0.4^{16}$ \\
\hline First generation techniques $\dagger$ & $0.6^{16}$ \\
\hline Operative complications & $0.0445^{14}$ \\
\hline Severe postoperative complications & $0.0292^{14}$ \\
\hline Death after operation & $0.0002^{14}$ \\
\hline Symptomatic after being well & $0.0002206 \ddagger \S$ \\
\hline Symptomatic after operative complications or severe postoperative complications & $0.01188 \S$ \\
\hline Second generation techniques & $0.0028^{15}$ \\
\hline Operative complications & $0.0007^{15}$ \\
\hline Severe postoperative complications & $0^{15}$ \\
\hline Death after operation & $0.0001864 \ddagger \S$ \\
\hline Symptomatic after being well & $0.05696 \ddagger \S$ \\
\hline Symptomatic after operative complications or severe postoperative complications & \\
\hline Mirena & $0.6806 \pi^{12}$ \\
\hline Proportion of women with coil in situ after 1 year & $0.4790 \pi^{13}$ \\
\hline Proportion of women with coli in situ after 5 years & $0.0168^{13}$ \\
\hline Insertion failure rate & $0.0358^{5}$ \\
\hline Hysterectomy** & $0.0102^{5}$ \\
\hline Operative complications & $0.0003^{5}$ \\
\hline Severe postoperative complications & \\
\hline Death after operation & \\
\hline &
\end{tabular}

*Proportions reversed and varied extensively in sensitivity analysis with extreme values; model results were no sensitive to this parameter.

†Complication and mortality rates in repeat ablation (rollerball) were double those in initial ablation. ${ }^{17}$

‡No of months remaining in model.

§Fit by calibration to individual patient data meta-analysis.

TFigures are original values as reported in papers. Failure per month in year 1 and years $2-5$ calculated.

${ }^{\star \star}$ Complication and mortality rates adjusted for "dysfunctional uterine bleeding" population only.

department life tables of England and Wales for the years 1998-2008. ${ }^{11}$

\section{Clinical assumptions and adverse events}

The lifespan of Mirena is assumed to be five years. ${ }^{11}$ If successful, treatment is repeated at five years. Treatment failure with Mirena is assumed to be more evident in the first year. ${ }^{12}{ }^{13} \mathrm{We}$ also assumed a $2 \%$ rate of insertion failure, where the procedure is repeated within a month. ${ }^{13}$ If Mirena is unsuccessful, women move to the second generation endometrial ablation as indicated by the pathway. No adverse events associated with Mirena were available in the literature. ${ }^{67}$

For first generation endometrial ablation techniques and hysterectomy we used large national audits of both as sources for perioperative and severe postoperative adverse events (table 2). ${ }^{145}$ Minor postoperative complications were not modelled. For second generation endometrial ablation techniques, we used complication rates of microwave endometrial ablation. ${ }^{15}$

Some of the data, specifically proportions in various health states at points in time after initial treatment, related to model outputs rather than model inputs. We applied a method that can be called "probabilistic calibration," whereby model inputs for the relevant parameters were sampled uniformly across the plausible range and cost and QALY outcomes were weighted according to the likelihood function comparing the model proportions in the various health states with the data.

A repeated intervention is assumed to indicate a failure in the initial procedure. The failure rate for endometrial ablation is about $25-35 \%$, inferred from the number of repeat ablations and hysterectomies that are carried out. This estimate does not include women who return to their general practitioner for medical treatment. ${ }^{7}$ We assumed that if endometrial ablation of any type fails, repeat ablation (with first generation devices only) or hysterectomy would be offered. In the model it is assumed that $60 \%$ of those with recurrent heavy menstrual bleeding (symptomatic state) will have a repeat endometrial ablation and $40 \%$ will have a hysterectomy. ${ }^{16}$ Only one repeat ablation is offered. We further assumed that if the treatment fails a second time, only hysterectomy is available. Complication rates for repeat ablations are assumed to be double those incurred for the initial ablation. ${ }^{17}$ We assumed that if symptoms do not recur within two years of the initial ablation, then they are unlikely to do so later, and therefore no repeat procedure takes place thereafter. Thus we have limited the time as to when a repeat procedure, ablation, or hysterectomy can occur to two years.

The transition probability for requiring a repeat procedure is time dependent and is reduced by a constant factor each month. This reflects a decreasing hazard, which is obvious from the individual patient data. ${ }^{7}$

We obtained information on perioperative and severe postoperative adverse events with first generation endometrial ablation techniques from the MISTLETOE study. ${ }^{14}$ For second generation techniques, we used complication rates with microwave endometrial ablation as a proxy ${ }^{15}$ because the complication rates from MISTLETOE for the second generation techniques refer to slightly outdated procedures and are no longer relevant. In using the complication rates with microwave endometrial ablation from the study by Parkin et $\mathrm{al}^{15}(\mathrm{n}=1400)$, we acknowledge that the true incidence of complications might be underestimated. All data reported in this study were from a

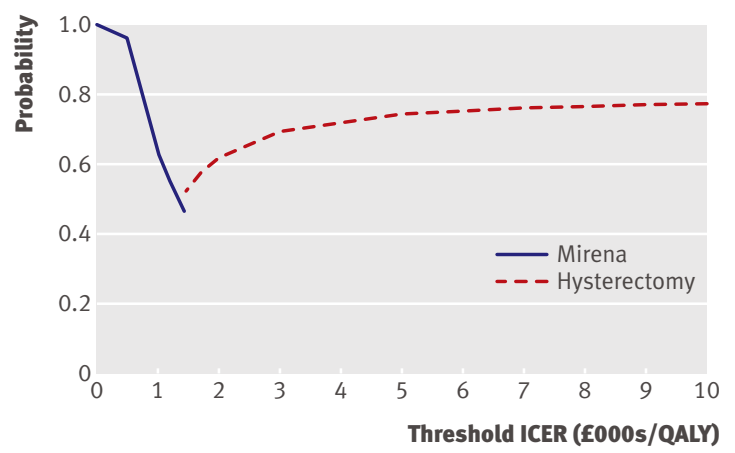

Fig 2 | Cost effectiveness acceptability frontier, showing probability that preferred option is cost effective (ICER=incremental cost effectiveness ratio) 
Table $3 \mid$ Costs associated with treatment for heavy menstrual bleeding in UK $£$ at 2008 prices

\begin{tabular}{|c|c|c|c|}
\hline Description & Unit cost & Details & Source \\
\hline First generation ablation techniques* & $£ 1238$ & $\begin{array}{l}\text { Costs in this study included pre-surgery treatment for endometrial ablations, technical equipment (varied } \\
\text { for each method), hospital costs, gynaecological outpatient costs, and re-treatment. Re-treatment } \\
\text { excluded from estimate because this is separate procedure included in model }\end{array}$ & Cameron, $1996^{22}$ \\
\hline Second generation ablation techniques $†$ & $£ 1101$ & $\begin{array}{l}\text { Source for costs of MEA and TBEA report by Garside. }{ }^{9} \text { Statistical weights for weighted cost mean obtained } \\
\text { from study reporting NHS hospital episode statistics of endometrial ablations from 1989-90 to 2005-5. }\end{array}$ & Garside, $2004^{9}$ \\
\hline Repeat ablation (rollerball) & $£ 1238$ & $\begin{array}{l}\text { Cost of repeat ablation was same as cost of first generation techniques described above. Additional cost } \\
\text { of GP consultation for referral from primary to secondary care included at } £ 46^{18}\end{array}$ & Cameron, $1996^{22}$ \\
\hline Hysterectomy & $£ 2162$ & $\begin{array}{l}\text { For women who had hysterectomy after failed repeat ablation, additional cost of GP consultation for } \\
\text { referral from primary to secondary care included at } £ 46^{18}\end{array}$ & Cameron, $1996^{22}$ \\
\hline GP visit for referral to secondary caref & $£ 46$ & - & PSSRU $^{19}$ \\
\hline \multicolumn{4}{|l|}{ Mirena } \\
\hline Total initial stage cost & $£ 130.27$ & $\begin{array}{l}\text { Procedure assumed to be performed in menstrual clinic as outpatient procedure. Total cost includes } \\
\text { those for device, initial consultation ( } 10 \text { minutes with nurse and } 30 \text { minutes with specialist registrar). and } \\
\text { sterile pack for use during Mirena insertion }\end{array}$ & \multirow{2}{*}{$\begin{array}{l}\text { BNF, National } \\
\text { Collaborating Center } \\
\text { for Women's and } \\
\text { Children's Health } \\
\text { CG44, PSSRU }\end{array}$} \\
\hline Discontinuation & $£ 28.34$ & Includes cost of consultation and consumables (sterile pack) used for removal of device & \\
\hline \multicolumn{4}{|l|}{ Adverse events§ } \\
\hline First generation ablation techniques & $£ 2161$ & See text & \multirow{3}{*}{$\begin{array}{l}\text { National Schedule of } \\
\text {-Reference Costs }\end{array}$} \\
\hline Second generation ablation techniques & $£ 1198$ & See text & \\
\hline Hysterectomy & $£ 3008$ & See text & \\
\hline \multicolumn{4}{|c|}{ 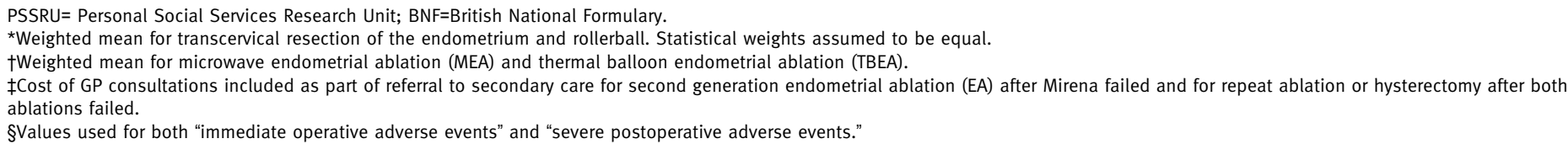 } \\
\hline
\end{tabular}

specialist centre and reported complication rates might not be representative of other second generation techniques.

\section{Resource use and costs}

All costs in the model are in UK $£$ (2008 value). We used appropriate indices to inflate some of the costs that were obtained from the literature. ${ }^{18}$ Table 3 shows the costs discounted at 3.5\% a year (as per NICE guidelines). ${ }^{8}$

The source for the costs of adverse events was NHS 2009 reference costs. ${ }^{19} \mathrm{We}$ used the same cost for perioperative and severe postoperative complications for each of the procedures included in the model. The varying severity of complications of the two different types of endometrial ablations and hysterectomy is also reflected in costs.

\section{Utility values}

Published sources were used to identify the quality of life weightings associated with each state in the model. ${ }^{132021}$ Table 4 describes these values in detail.

The quality of life data show that heavy menstrual bleeding is associated with a quality of life value of 0.50 , which means that women who have this condition have reported that they feel a loss in terms of quality of life value that is equivalent to half a year at full health. If women have a successful first generation ablation they move to the "well" state associated with a quality of life value of $0.73 .{ }^{21}$ In contrast, after a successful second generation ablation, women move to the "well" state associated with a quality of life value of 0.84 . This is an assumption made in the absence of available data, but relates to the same "well" state as after successful experience with Mirena. This was based on the fact that, if they are successful, second generation techniques (generally speaking) perform better, are less invasive, and have fewer adverse events. ${ }^{7}$ If ablations of any type are unsuccessful and a repeat ablation is required, however, they are always first generation ablations and the associated quality of life value is 0.73 .

The quality of life value for convalescence after hysterectomy is estimated at $0.74 .^{2022} \mathrm{We}$ assume that this quality of life is not reached until one week after hysterectomy and assumed a zero quality of life value for the week immediately after the operation. This gives an average quality of life over the month of 0.56 . After a successful hysterectomy, women move to the "well" state associated with a quality of life value of $0.88 .^{13}$

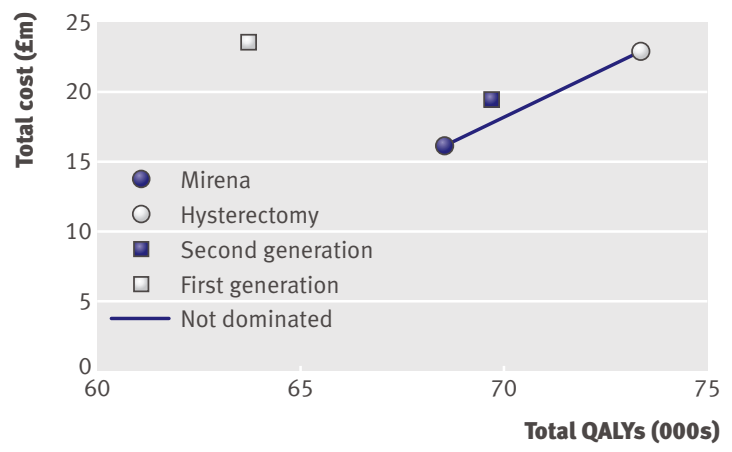

Fig 3 | Base case deterministic results of cost effectiveness of different treatments for heavy menstrual bleeding (Mirena, hysterectomy, and first and second generation ablation techniques) 
Table $4 \mid$ Health state utilities used in model to determine cost effectiveness of different treatments for heavy menstrual bleeding

\begin{tabular}{|c|c|c|c|c|}
\hline & $\begin{array}{c}\text { Utility } \\
\text { (SE or } 95 \% \mathrm{Cl})\end{array}$ & Median* & Source & Comment \\
\hline Menorrhagia & $0.50($ SE 0.04$)$ & 0.55 & Sculpher, $1998^{20}$ & - \\
\hline Dead & 0 & - & - & By definition \\
\hline Hysterectomy & 0.56 & - & - & Assumed $25 \%$ less than "convalescence after hysterectomy" \\
\hline Well after hysterectomy & $0.88(0.75$ to 0.95$) \dagger$ & - & Hurskainen, $2004^{13}$ & - \\
\hline Convalescence after hysterectomy & 0.74 (SE 0.05) & 0.95 & Sculpher, $1998^{20}$ & - \\
\hline Severe complications after hysterectomy & 0.49 & - & Clegg, $2007^{21}$ & - \\
\hline First generation ablation techniques & 0.76 (SE 0.04) & 0.85 & Sculpher, $1998^{20}$ & Includes "convalescence after first generation techniques" \\
\hline Well after first generation techniques & 0.73 (SE 0.04) & 0.90 & Sculpher, $1998^{20}$ & - \\
\hline Severe complications after first generation techniques & 0.49 & - & - & Same as complications after hysterectomy \\
\hline Symptomatic after first generation techniques & 0.50 (SE 0.04) & 0.55 & Sculpher, $1998^{20}$ & Same as "menorrhagia" \\
\hline Second generation ablation techniques & 0.76 (SE 0.04) & - & - & Assumed same as first generation techniques \\
\hline Well after second generation techniques & $0.84(0.73$ to 0.93$) \dagger$ & - & - & Same as Mirena \\
\hline Severe complications after second generation techniques & 0.49 & - & - & Same as complications after hysterectomy \\
\hline Symptomatic after second generation techniques & 0.50 (SE 0.04) & 0.55 & Sculpher, $1998^{20}$ & Same as "menorrhagia" \\
\hline Repeat ablation (rollerball) & 0.76 (SE 0.04) & - & - & Includes convalescence after first generation techniques \\
\hline Well after repeat ablation & 0.73 (SE 0.04) & 0.90 & Sculpher, $1998^{20}$ & - \\
\hline Severe complications after repeat ablation & 0.49 & - & - & Same as complications after hysterectomy \\
\hline Symptomatic after repeat ablation & 0.50 (SE 0.04) & 0.55 & Sculpher, $1998^{20}$ & Same as "menorrhagia" \\
\hline Mirena & $0.84(0.73$ to 0.93$) \dagger$ & - & Hurskainen, $2004^{13}$ & Same as "well after Mirena" assumption \\
\hline Well after Mirena & $0.84(0.73$ to 0.93$) \dagger$ & - & Hurskainen, $2004^{13}$ & - \\
\hline Symptomatic after Mirena & 0.50 (SE 0.04) & - & Sculpher, $1998^{20}$ & Same as "menorrhagia" \\
\hline
\end{tabular}

For costs, we aggregated according to the distributions at the start of each cycle. This is necessary to account for the full costs of initial treatment.

\section{Analysis}

All analyses are carried out from the perspective of the UK NHS and are reported in terms of incremental cost effectiveness ratios presented in terms of cost per quality adjusted life year (QALY). Dominance in the results will exist if one strategy is found to be both cheaper and more effective in terms of producing more QALYs.

We assessed uncertainty in the model parameters through probabilistic sensitivity analysis. In its most common form, this assigns to each input parameter a specific distribution and, by drawing randomly from those distributions, generates a large number of estimates of mean cost and effectiveness. These estimates are then used to form an empirical joint distribution of the differences in cost and effectiveness between inter ventions. $^{2324}$

We carried out one subgroup analysis and two alternative one way deterministic sensitivity analyses. The subgroup analysis was carried out on the basis of the length of the uterine cavity, on the rationale that ablation (as opposed to hysterectomy) is more likely to be successful in women with a shorter cavity. ${ }^{7}$

In the first deterministic sensitivity analysis we changed utilities from the base case, in which the mean utility values are used, to an analysis based on reported median values from the study by Sculpher ${ }^{20}$ (table 4). Use of the mean scores is most appropriate in economic evaluation because if outliers are ignored it could lead to the cost effectiveness analysis underestimating costs or overestimating effects. Other published studies used median values reported by Sculpher, ${ }^{20}$ and not means, without explanation or justification. We believe this use to be inappropriate and are unclear how the medians were estimated. ${ }^{9}$ In the second deterministic sensitivity analysis we used the "median" quality of life values from Sculpher ${ }^{20}$ and set the quality of life value for the "well" state after the intervention to the same value for both ablation strategies and Mirena (0.90).

\section{RESULTS}

Table 5 presents a summary of the deterministic results. The results show that the strategy that uses first generation endometrial ablation as the first intervention of the pathway is dominated by all the other strategies as it is both more expensive and less effective in terms of producing QALYs. The strategy that adopts hysterectomy as the first and only intervention produces the most QALYs. In comparison with the strategy that uses Mirena first, hysterectomy is more expensive but generates more QALYs. The incremental cost effectiveness ratio (ICER) representing the value of the additional benefit of the hysterectomy strategy compared with Mirena is $£ 1440$ (€1633, $\$ 2350)$ per additional QALY. The hysterectomy strategy also produces more QALYs than the second generation endometrial ablation strategy and the estimated incremental cost effectiveness ratio for this comparison is $£ 970$ per additional QALY. 
Table $5 \mid$ Summary of deterministic base case, subgroup, and sensitivity analyses of model to determine cost effectiveness of different treatments for heavy menstrual bleeding

$\begin{array}{cll}\text { Total costs per } & \text { Total QALYs } & \begin{array}{c}\text { Incremental cost } \\ \text { effectiveness } \\ \text { ratio (ICER) } \\ \text { ( } v \text { hysterectomy) }\end{array}\end{array}$

Summary of base case deterministic results

\begin{tabular}{llcc}
\hline First generation endometrial ablation & 23590 & 63745 & Dominated \\
\hline Second generation endometrial ablation & 19470 & 69678 & 970 \\
\hline Mirena & 16150 & 68566 & 1440 \\
\hline Hysterectomy & 23000 & 73332 & - \\
\hline
\end{tabular}

Summary of subgroup analysis based on short uterine cavity length

\begin{tabular}{llll}
\hline First generation endometrial ablation & 21356 & 63143 & 161 \\
\hline Second generation endometrial ablation & 19264 & 69582 & 996 \\
\hline Mirena & 15667 & 68201 & 1429 \\
\hline
\end{tabular}

\begin{tabular}{llll}
\hline Hysterectomy & 23000 & 73332 & -
\end{tabular}

Summary of subgroup analysis based on long uterine cavity length

\begin{tabular}{llcc}
\hline First generation endometrial ablation & 20104 & 62809 & 275 \\
\hline Second generation endometrial ablation & 17986 & 69655 & 1364 \\
\hline Mirena & 15158 & 68558 & 1642 \\
\hline Hysterectomy & 23000 & 73332 & -
\end{tabular}

Deterministic sensitivity analysis 1: where mean values are substituted by median values*

\begin{tabular}{llcc}
\hline First generation endometrial ablation & 23588 & 74218 & 2225 \\
\hline Second generation endometrial ablation & 19466 & 74402 & Dominates \\
\hline Mirena & 16151 & 71089 & 2391 \\
\hline Hysterectomy & 23000 & 73954 & - \\
\hline
\end{tabular}

Deterministic sensitivity analysis 2: where mean values are substituted by median values $\dagger$

\begin{tabular}{llcc}
\hline First generation endometrial ablation & 23588 & 74218 & 2225 \\
\hline Second generation endometrial ablation & 19466 & 74402 & Dominates \\
\hline Mirena & 16151 & 73488 & 14683 \\
\hline Hysterectomy & 23000 & 73954 & -
\end{tabular}

*Assumes that well after intervention for first and second generation ablation are equal but not for Mirena. †Assumes that well post intervention is same for both ablation strategies and Mirena.

The Mirena strategy dominates the first generation endometrial ablation strategy, being cheaper and more effective in producing QALYs. But though it is also cheaper than second generation endometrial ablation, in this comparison it produces fewer QALYs. The incremental cost effectiveness ratio for the second generation endometrial ablation versus Mirena is $£ 2980$ per additional QALY.

Figure 2 shows the result of the probabilistic sensitivity analysis. Detailed interpretation of this analysis and additional value of information analysis is presented elsewhere. ${ }^{6}$ Briefly, it shows the probability that the preferred option is cost effective for any given threshold incremental cost effectiveness ratio for all but a few replications - and the few account for a negligible probability. Mirena was the least costly option and, for low acceptable threshold incremental cost effectiveness ratios, Mirena is preferred with certainty within this model given its assumptions. But as the threshold incremental cost effectiveness ratio increases hysterectomy becomes the preferred option.

In some replications of the model (accounting for $20 \%$ of the probability), hysterectomy was not the most effective option (in terms of total number of QALYs). At an incremental cost effectiveness ratio of $£ 1440$, the preferred option changes from Mirena to hysterectomy, so there is a discontinuity in the cost effectiveness acceptability curve.

In the subgroup analysis, carried out to explore the impact of the length of the uterine cavity on cost effectiveness of the alternative interventions for heavy menstrual bleeding, we carried out two separate analyses and a corresponding probabilistic sensitivity analysis. The results of the subgroup analysis showed a small effect of shorter and longer uterine cavity length, which was in the same direction for both. For both cases the results moved slightly so that first generation ablation was no longer "dominated" by hysterectomy and the incremental cost per additional QALY of hysterectomy compared with other strategies was slightly higher (less favourable) than in the base case. There is, however, unlikely to be a change in the decision based on these results and hysterectomy remains the preferred strategy. The results of the probabilistic sensitivity analysis reinforced the results of this deterministic subgroup analysis and are not presented.

In a further deterministic sensitivity analysis, we changed the utilities from the base case in which the mean utility values are used, to reported median values. In the first deterministic sensitivity analysis we used the "median" quality of life values from Sculpher ${ }^{20}$ and assumed the quality of life scores as a result of first and second generation ablation were equal based on median values (well after first or second generation endometrial ablation 0.90). The key change in results compared with the base case is that there is a clear shift away from the hysterectomy strategy in favour of second generation endometrial ablation. This dominates first generation endometrial ablation as before, but now also dominates hysterectomy. Meanwhile, in this sensitivity analysis the incremental cost effectiveness ratio for second generation endometrial ablation versus the Mirena strategy was $£ 1000$ per additional QALY.

The results of the second deterministic sensitivity analysis are similar to those presented in the first. Once again the strategy of second generation endometrial ablation dominates first generation endometrial ablation and hysterectomy, in contrast with the base case. The incremental cost effectiveness ratio for second generation endometrial ablation versus Mirena is £3624 per additional QALY.

Figures 3 and 4 summarise and compare the key findings from changing the utility values (presented in the first and second sensitivity analyses) with the base case. Figure 3 shows that with baseline (mean) utilities, Mirena is the least costly strategy and hysterectomy the most effective. The strategy that starts with first generation endometrial ablation is simply dominated by all of the other strategies. The strategy that starts with second generation endometrial ablation is excluded by extended dominance between Mirena and hysterectomy.

Figure 4 shows the same costs for all strategies as figure 3 but the total QALYs are increased. By using the median utility values, second generation ablation now becomes the most effective strategy: both first 


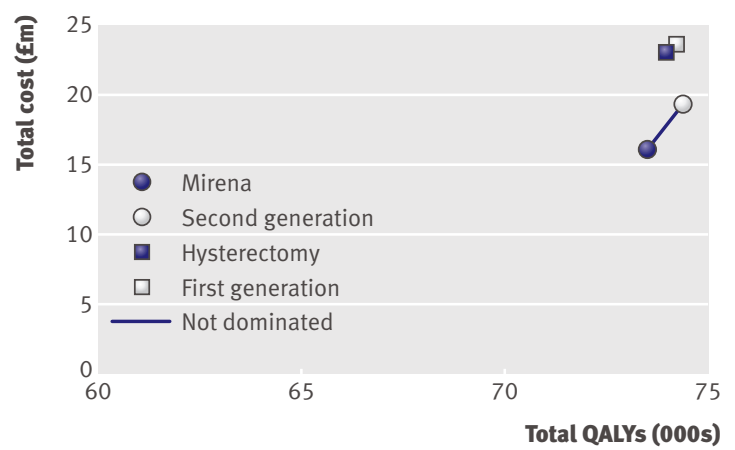

Fig 4 | Deterministic sensitivity analysis with median utility values instead of means for cost effectiveness of different treatments for heavy menstrual bleeding (Mirena, hysterectomy, and first and second generation ablation techniques)

generation endometrial ablation and hysterectomy are simply dominated by second generation endometrial ablation.

\section{DISCUSSION}

\section{Statement of principal findings}

The results of the base case analysis show that hysterectomy is the preferred strategy as the first intervention for heavy menstrual bleeding. Hysterectomy dominates the strategy that uses first generation endometrial ablation as the initial intervention. Although hysterectomy is more expensive, it produces more QALYs relative to other remaining strategies and is likely to be considered cost effective: the incremental cost effectiveness ratio for hysterectomy compared with Mirena is $£ 1440$ per additional QALY. These results suggest that hysterectomy first would be considered the preferred strategy in light of the acceptable thresholds used by NICE, which tends to accept new technologies if the incremental cost effectiveness ratio is within $£ 20000$ per additional QALY.

Our main results suggesting the relative cost effectiveness of hysterectomy were robust to all the sensitivity and subgroup analyses, with the exception of the sensitivity analysis carried out on the utility data. This was based on an analysis that used the reported values of utilities that are available in the published literature, specifically the "mean" reported utility values, which is appropriate. ${ }^{2526}$

\section{Strengths and limitations}

The major strength of the economic component of this study is that it is based on a sophisticated Markov model, which was informed by data from an individual patient level data meta-analysis of randomised trials. A multidisciplinary team including economists, expert clinicians, and statisticians provided input into the model structure primarily based on the evidence in the literature. All assumptions used in the model were based on the available evidence as far as possible. All required assumptions were agreed with the team before the analysis was carried out and without knowledge of how these assumptions might affect the results.
In terms of limitations, it is possible that we did not include all aspects of costs and outcome as the utilities used are likely to reflect the satisfaction of the outcomes only. Once women have had a hysterectomy, for example, their satisfaction is high because, in contrast with the other interventions, they experience no bleeding at all. But the utility measure does not capture the anxiety before hysterectomy associated with major surgery and general anaesthetic. Such anxieties can lead to decisions that avoid major surgery as a first step and to try other less invasive options for as long as possible. The perspective of the analysis does not include the costs to women associated with six to eight weeks' convalescence after hysterectomy. Furthermore, the model's time horizon and the lack of long term data exclude possible effects of long term complications such as urinary stress incontinence for which surgery is required. ${ }^{27}$

\section{Strengths, weaknesses, and assumptions in relation to other studies}

With regard to the utility values that have been used in the current study the following points are worth noting. First, the paper by Sculpher ${ }^{20}$ has been extensively referenced in the literature. Other studies, including that by Garside et al, ${ }^{9}$ have used the median values from that paper and not the means, seemingly without justification or a critique of the face validity of these data. Furthermore, for economic evaluation it is the mean values that are most appropriate to use as it is considered important to capture outliers to avoid underestimating costs or overestimating benefits. ${ }^{2526}$

Our results suggest that hysterectomy is the most cost effective strategy, but we must emphasise the uncertainty in the utility data. Mirena has not been extensively evaluated, and there are only limited data available on long term follow-up.

\section{Comparison with other studies}

The results of the model based economic evaluation reported by Garside et al also showed hysterectomy was the most cost effective strategy for treating heavy menstrual bleeding. ${ }^{9}$ They compared second generation with first generation ablative techniques and hysterectomy. Mirena was not included in their comparative analysis. When compared with hysterectomy, second generation ablative techniques were found to be less costly but also provided fewer QALYs. The authors used median, not mean, utility values in their analysis but without justification. They reported that the results of their model were highly sensitive to the utility values associated with being well after ablation and recommended that results are interpreted with caution because of this sensitivity. ${ }^{9}$ In our sensitivity analysis, when we used the same median value for the utilities, as opposed to the means, the results showed that second generation endometrial ablation was the most cost effective strategy.

Our results do not concur with the result of the Finnish trial by Hurskainen et al, which compared Mirena with hysterectomy and found Mirena to be cost 


\section{WHAT IS ALREADY KNOWN ON THIS TOPIC}

Less invasive alternatives to hysterectomy for the treatment of heavy menstrual bleeding, such as endometrial ablation and Mirena, have become increasing popular

As second generation endometrial ablation techniques and Mirena are cheaper and less invasive, they are likely to be preferred to hysterectomy

\section{WHAT THIS STUDY ADDS}

Second generation non-hysteroscopic endometrial ablation and Mirena are both less costly and produce more QALYS than first generation techniques

Based on current best available evidence Mirena is not a cost effective strategy compared with hysterectomy

Based on all available evidence on effectiveness, cost, and utility values, hysterectomy produces cost effectiveness ratios that are likely to be accepted by decision makers

effective at five years. ${ }^{13}$ There was no significant difference in quality of life scores at five years, as measured by the EQ-5D instrument, between the two treatment groups. But this is unsurprising as $40 \%$ of women in the Mirena arm went on to have a hysterectomy and completed EQ-5D at the end of treatment. ${ }^{13}$ It is also a cause for concern that mean direct costs in the Mirena arm remained significantly lower $(\$ 1892)$ than the hysterectomy arm (\$2787), despite the substantial number subsequently undergoing hysterectomy.

An economic modelling study undertaken to inform NICE guidelines ${ }^{8}$ suggested that Mirena is cost effective when compared with both hormonal and non-hormonal treatment. Mirena generated more QALYs at a lower cost than any other medical or surgical treatment strategy considered. Our model differed from the NICE model in terms of the assumptions. The NICE model assumed that within the five year lifespan of Mirena, some women who experienced failure with Mirena would move straight to hysterectomy (based on data from Hurskainen et $\left.\mathrm{al}^{13}\right)$. In contrast, in our study, our assumption (based on advice from clinical colleagues) was that all women who experienced failure with the Mirena strategy would, in the first instance, follow the second generation endometrial ablation pathway. This helps to explain the difference in results and the relative preference in our analysis for hysterectomy over Mirena. Furthermore, it also highlights the importance of hysterectomy, as integral to NICE guidance supporting Mirena in the first instance is the belief that hysterectomy is available if Mirena fails.

An implicit assumption in this and other similar studies is that there exists equivalent ability to undertake all these procedures both from a time and skill base, but this is unlikely to be true. For example, Mirena can be fitted in primary care; second generation ablative techniques, while requiring use of a hospital, can be carried out by specialist after minimal training in an outpatient setting; but hysterectomy can be undertaken only by more highly trained specialists in inpatient theatre suites. While these differences are reflected in the costs of the procedures used in the analyses, constraints in available capacity and skills are not.

\section{Implications}

Our results suggest that, based on current best available data, which are limited, Mirena is not a robust cost effective strategy compared with hysterectomy. These results contradict current opinion and practice in gynaecology, which has seen a reduction in the rate of hysterectomy for heavy menstrual bleeding over the past decade or so. Our evaluation is based on the best available data and the assumptions used in the model were made before the analysis and are unbiased. The data, however, might not reflect the decision making process between women and doctors for whom minimal risks and relatively quick and convenient treatments might offset the higher failure rates associated with Mirena initially, knowing that a more definitive treatment is still available. This leads to a potential conflict between an individual approach based on choice and a utilitarian one based on maximising gains for society.

\section{Unanswered questions for future research}

We used a sophisticated model, data from an individual patient data meta-analysis, and all available data on quality of life associated with the available interventions for the outcomes for alternative treatments for heavy menstrual bleeding.

One of the main causes of uncertainty is with regard to the utility values associated with alternative interventions and their success. There would be little value in future studies comparing the outcomes and costs of any alternative interventions to treat women for heavy menstrual bleeding without undertaking a comprehensive study to clarify the quality of life associated with the outcomes of the alternative interventions.

Our results show that more robust clinical data would enhance clinical decision making, in particular with regard to interventions such as Mirena, for which there are limited follow-up data. Some of the current authors are involved in the Birmingham based ECLIPSE trial, which is a large UK funded (NCCHTA) trial that will provide evidence on whether Mirena is preferable to standard oral treatments for heavy menstrual bleeding. Several approaches to assessing quality of life issues and preferences are currently being considered.

Preferences of women and clinicians will continue to be extremely influential in decision making. Many clinicians believe that a "one size fits all" approach to the treatment of heavy menstrual bleeding is impossible. As individual choices can determine perceived success, eliciting preferences is also extremely relevant in this context. ${ }^{28}$

Contributors: TER, PB, SB, and JD contributed to the design of the whole project and obtained funding. TER and PB designed the model based cost effectiveness analysis. TER prepared the manuscript as lead writer. AT under the supervision of PB constructed the model with advice from KC and SB. AT under the supervision of TER and PB identified and collected the required data on costs and effectiveness for the model and carried out the analysis. LM, JD, KC, RC, and SB provided the relevant data from the individual patient data meta-analysis. TR, PB, and AT interpreted the results with assistance from $K C$ and $S B$. TR is guarantor. 
Funding: This study was funded by the National Institute for Health Research Health Technology Assessment Programme (05/45/02) Competing interests: All authors have completed the Unified Competing Interest form at www.icmje.org/coi_disclosure.pdf (available on request from the corresponding author) and declare: no support from any organisation for the submitted work; no financial relationships with any organisations that might have an interest in the submitted work in the previous three years; no other relationships or activities that could appear to have influenced the submitted work.

Ethical approval: Not required.

Data sharing: No additional data available.

1 Rees MC. Role of menstrual blood loss measurements in management of complaints of excessive menstrual bleeding. $\mathrm{Br}$ J Obstet Gynaecol 1991;98:327-8.

2 National Statistics Online. Census 2001. 2002. www.statistics.gov. uk/census2001/pop2001/england_wales.asp.

3 Coulter A, Peto V, Jenkinson C. Quality of life and patient satisfaction following treatment for menorrhagia. Fam Pract 1994;11:394-401.

4 Vessey MP, Villard-Mackintosh L, McPherson K, Coulter A, Yeates D. The epidemiology of hysterectomy: findings in a large cohort study. BrJ Obstet Gynaecol 1992;99:402-5.

5 Maresh MJ, Metcalfe MA, McPherson K, Overton C, Hall V, Hargreaves J, et al. The VALUE national hysterectomy study: description of the patients and their surgery. BJOG 2002;109:302-12.

6 Bhattacharya S, Middleton LJ, Tsourapas A, Lee AJ, Champaneria R, Daniels JP, et al. Effectiveness and cost effectiveness of hysterectomy, endometrial ablation and Mirena for heavy menstrual bleeding. Health Technol Assess (in press).

7 Middleton LI, Champaneria R, Daniels JP, Bhattacharya S, Cooper KG, Hilken $\mathrm{NH}$, et al. Hysterectomy, endometrial destruction and Mirena for heavy menstrual bleeding: a systematic review and individual patient data meta-analysis. BM/ 2010;341:c3929.

8 National Institute for Health and Clinical Excellence. IPG104 impedance-controlled bipolar radiofrequency ablation for menorrhagia: guidance. 2007. http://guidance.nice.org.uk/IPG104/ Guidance/pdf/English.

9 Garside R, Stein K, Wyatt K, Round A, Price A. The effectiveness and cost-effectiveness of microwave and thermal balloon endometrial ablation for heavy menstrual bleeding: a systematic review and economic modelling. Health Technol Assess 2004;8:iii,1-155.

10 Sambrook AM, Jack SA, Cooper KG. Outpatient microwave endometrial ablation: 5-year follow-up of a randomised controlled trial without endometrial preparation versus standard day surgery with endometrial preparation. BJOG 2010;117:493-6.

11 Government Actuary's Department. Life tables. GAD, 2009.

12 Hurskainen R, Teperi J, Rissanen P, Aalto AM, Grenman S, Kivela A, et al. Quality of life and cost-effectiveness of levonorgestrel-releasing intrauterine system versus hysterectomy for treatment of menorrhagia: a randomised trial. Lancet 2001;27;357:273-7.

13 Hurskainen R, Teperi J, Rissanen P, Aalto AM, Grenman S, Kivela A, et al. Clinical outcomes and costs with the levonorgestrel-releasing intrauterine system or hysterectomy for treatment of menorrhagiarandomized trial 5-year follow-up. JAMA 2004;291:1456-63.

14 Overton C, Hargreaves J, Maresh M. A national survey of the complications of endometrial destruction for menstrual disorders: the MISTLETOE study. Minimally Invasive Surgical TechniquesLaser, EndoThermal or Endoresection. Br J Obstet Gynaecol 1997;104:1351-9.

15 Parkin DE. Microwave endometrial ablation (MEA (TM)): a safe technique? Complication data from a prospective series of 1400 cases. Gynaecol Endosc 2000;9:385-8.

16 Cooper KG, Jack SA, Parkin DE, Grant AM. Five-year follow up of women randomised to medical management or transcervical resection of the endometrium as treatment for heavy menses. $\mathrm{Br}$ J Obstet Gynaecol 2001;108:1222-8.

17 MacLean-Fraser E, Penava D, Vilos GA. Perioperative complication rates of primary and repeat hysteroscopic endometrial ablations. I Am Assoc Gynecol Laparosc 2002;9:175-7.

18 Curtis L. Unit costs of health and social care. Personal Social Services Research Unit, 2008.

19 Personal Social Services Research Unit. Home page. 2010. www. pssru.ac.uk/.

20 Sculpher M. A cost-utility analysis of abdominal hysterectomy versus transcervical endometrial resection for the surgical treatment of menorrhagia. Int J Technol Assess Health Care 1998;14:302-19.

21 Clegg JP, Guest JF, Hurskainen R. Cost-utility of levonorgestrel intrauterine system compared with hysterectomy and second generation endometrial ablative techniques in managing patients with menorrhagia in the UK. Curr Med Res Opin 2007;23:1637-48.

22 Cameron IM, Mollison J, Pinion SB, Atherton Naji A, Buckingham K, Torgerson D. A cost comparison of hysterectomy and hysteroscopic surgery for the treatment of menorrhagia. Eur J Obstet Gynecol Reprod Biol 1996;70:87-92.

23 Briggs A, Sculpher M, Buxton M. Uncertainty in the economic evaluation of health-care technologies-the role of sensitivity analysis. Health Econ 1994;3:95-104.

24 Briggs AH. Handling uncertainty in cost-effectiveness models. Pharmacoeconomics 2000;17:479-500.

25 Torrance GW. Measurement of health state utilities for economic appraisal. J Health Econ 1986;5:1-30.

26 Thompson SG, Barber JA. How should cost data in pragmatic randomised trials be analysed? BMJ 2000;320:1197-200.

27 Brown JS, Sawaya G, Thom DH, Grady D. Hysterectomy and urinary incontinence: a systematic review. Lancet 2000;356:535-9.

28 Cooper KG, Garratt AM, Grant AM. The impact of using a partially randomised patient preference trial design when evaluating alternative managements for heavy menstrual bleeding. Br J Obstet Gynaecol 1997;104:1360-6.

Accepted: 16 February 2011 